\title{
The effect of nutritional management of dairy cows post-calving and yeast supplementation on milk fatty acid profiles in the first eight weeks of lactation
}

R Alibrahim, F.M Mulligan, R.A Palladino, K.M Pierce

University College Dublin, Lyons Research Farm, Newcastle, Co. Dublin, Ireland

Email: karina.pierce@ucd.ie

Introduction There is increased focus on earlier turnout of cows to pasture post-calving. However, nutritional management of cows in early lactation can influence milk production and milk composition throughout lactation. Through effects on rumen $\mathrm{pH}$ (Dawson and Hopkins, 1991), yeast supplementation (YS) may influence biohydrogenation of fatty acids (FA) in the rumen and therefore, milk FA profiles. The objective of this experiment was to evaluate the impact of nutritional management of the dairy cow in early lactation on subsequent milk FA profiles. This research is part of a larger study investigating the effect of abrupt introduction of cows to pasture immediately at calving with a more delayed introduction to pasture, and the effect of dietary YS (Yea-Sacc ${ }^{1026}$ TS, Alltech, INC., Nashville, KY, USA) on rumen physiology at this time.

Material and methods The experiment was designed as a $2 \times 2$ factorial (grass $v s$ TMR in early lactation +/- YS). The yeast was offered at $10 \mathrm{~g} / \mathrm{hd} / \mathrm{d} \times 10^{8} \mathrm{CFU}$ of live strain $S$. cerevisiae ${ }^{1026} / \mathrm{g}$, Yea-Sacc ${ }^{1026} \mathrm{TS}$. Treatments were: 1) Abrupt introduction to pasture post-calving (AP) + YS; 2) AP - YS; 3) TMR for 21 days post-calving (TMR21) + YS and 4) TMR21 - YS. In the dry period (60 days pre-calving) all cows were fed grass silage (GS) ad-libitum. The TMR was provided ad libitum and consisted of 50\% maize silage, $45 \% \mathrm{GS}$, and $5 \%$ wheat straw, and $8 \mathrm{~kg}$ concentrate $+/-$ YS. At day 22 post calving, TMR2 1 cows (+/- YS) received the same diets as AP (+/- YS) cows. Pasture allowance of $20 \mathrm{~kg}$ DM/hd/d (measured at a cutting high of $4 \mathrm{~cm}$ ) was maintained across the trial period. Grazing cows were supplemented with concentrate $(+/-$ YS $)$ at rate of $4 \mathrm{~kg} / \mathrm{hd} / \mathrm{d}$. Cows were milked $\mathrm{x} 2$ daily, and milk yield was recorded at each milking. Milk samples were collected weekly for an 8 week period and were mixed according to their am and pm yield. Feed and milk FA were analyzed by GC according to Palladino et al. (2009). Data were analyzed using PROC MIXED of SAS.

Results Cows fed TMR21 had higher short chain FA (SFA) $(\mathrm{P}<0.01)$ and medium chain FA $(\mathrm{MCFA})(\mathrm{P}<0.05)$ whilst unsaturated FA(UFA) $(\mathrm{P}<0.05)$, UFA:SFA $(\mathrm{P}<0.01)$, and long chain FA (LCFA) $(\mathrm{P}<0.05)$ were lower compared to AP cows (Table 1). Cis-9 C18:1 was in also higher in milk from AP cows. Yeast supplementation had no effect on milk FA profiles in the current experiment and there was no interaction between diet and YS.

Table 1 Effect of early lactation diet and YS on milk FA composition in the first 8 weeks of lactation

\begin{tabular}{|c|c|c|c|c|c|c|c|c|c|}
\hline \multirow[t]{2}{*}{ Item $(\mathrm{g} / \mathrm{kg}$ of Total FA) } & \multicolumn{2}{|c|}{ Yeast } & \multicolumn{4}{|c|}{ Diet } & \multicolumn{3}{|c|}{ Significance $^{2}$} \\
\hline & + & - & SED $^{1}$ & Grass & TMR & SED & Yeast & Diet & YeastxDiet \\
\hline cis-9 C18:1 & 219.1 & 236.5 & 10.80 & $254.4^{\mathrm{a}}$ & $201.2^{\mathrm{b}}$ & 16.11 & NS & $* *$ & $\mathrm{NS}$ \\
\hline cis-9 trans-11 C18:2 (CLA) & 8.1 & 7.6 & 0.87 & 7.9 & 7.7 & 1.30 & NS & NS & NS \\
\hline $\mathrm{SFA}^{3}$ & 642.2 & 621.5 & 13.34 & $600.9^{\mathrm{b}}$ & $662.8^{\mathrm{a}}$ & 19.91 & NS & $* *$ & NS \\
\hline UFA & 283.0 & 300.4 & 13.77 & $321.4^{\mathrm{a}}$ & $262.1^{\mathrm{b}}$ & 20.56 & NS & $*$ & NS \\
\hline UFA:SFA & 0.46 & 0.50 & 0.029 & $0.55^{\mathrm{a}}$ & $0.41^{\mathrm{b}}$ & 0.043 & NS & $* *$ & NS \\
\hline $\mathrm{SCFA}^{4}$ & 147.3 & 133.1 & 12.93 & 132.5 & 147.9 & 19.30 & NS & NS & NS \\
\hline $\mathrm{MCFA}^{5}$ & 452.9 & 445.8 & 7.03 & $423.3^{\mathrm{b}}$ & $471.4^{\mathrm{a}}$ & 18.97 & NS & $*$ & NS \\
\hline $\mathrm{LCFA}^{6}$ & 330.7 & 348.3 & 14.97 & $372.1^{\mathrm{a}}$ & $306.9^{\mathrm{b}}$ & 22.36 & NS & $*$ & NS \\
\hline
\end{tabular}

${ }^{\mathrm{a}, \mathrm{b}}$ Means within a row with different superscripts differs $(\mathrm{P}<0.05) ;{ }^{1}$ Standard error of the differences; ${ }^{2} \mathrm{NS}=$ not significant; $*=\mathrm{P}<0.05 ; * *=\mathrm{P}<0.01 ;{ }^{3} \mathrm{Level}$ of significance correspond to transformed variable; ${ }^{4} \mathrm{SCFA} ; \mathrm{C} 4: 0$ to $\mathrm{C} 8: 0 ;{ }^{5} \mathrm{MCFA} ; \mathrm{C} 10: 0$ to $\mathrm{C} 16: 1 ;{ }^{6} \mathrm{LCFA} ; \mathrm{C} 17: 0$ to $\mathrm{C} 22: 6$

Conclusions Dietary management in early lactation influenced milk fatty acid profiles. Cows offered grass immediately post-calving had higher LCFA, lower SFA, MCFA and UFA:SFA compared to cows offered TMR for the first 3 weeks post-calving. Yeast supplementation had no effect on milk FA profiles in the current experiment.

\section{References}

Dawson, K. A. and D. M. Hopkins. 1991. Journal of Animal Science 69 (Suppl. 1), 531.

Palladino, R.A, M. O’Donovan, J. J. Murphy, M. McEvoy, J. Callan, T. M. Boland and D. A. Kenny. 2009. Journal of Dairy Science. 92, 5212-5223

Statistical Institute. 2006. Users Guide: Statistics. Version 9.1. SAS Institute, Cary, NC. 